\title{
ASSESSMENT OF LEVEL OF AWARENESS FOR DIABETES MELLITUS, ITS SYSTEMIC AND OCULAR COMPLICATIONS: A QUESTIONNAIRE-BASED SURVEY AT TERTIARY CARE CENTRE OF KUMAON REGION
}

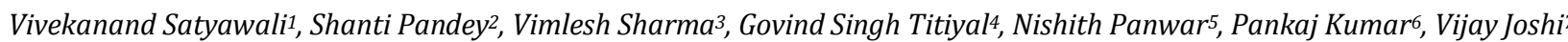 \\ ${ }^{1}$ Associate Professor, Department of Medicine, Government Medical College, Haldwani, Nainital, Uttarakhand. \\ 2Associate Professor, Department of Ophthalmology, Government Medical College, Haldwani, Nainital, Uttarakhand. \\ ${ }_{3}^{3}$ Assistant Professor, Department of Ophthalmology, Government Medical College, Haldwani, Nainital, Uttarakhand. \\ 4 Professor, Department of Ophthalmology, Government Medical College, Haldwani, Nainital, Uttarakhand. \\ 53rd Year Postgraduate, Department of Ophthalmology, Government Medical College, Haldwani, Nainital, Uttarakhand. \\ ${ }^{6}{ }^{\text {rd }}$ Year Postgraduate, Department of Ophthalmology, Government Medical College, Haldwani, Nainital, Uttarakhand. \\ ${ }^{7}$ Ophthalmologist, Provincial Medical Services, Pithoragarh, Uttarakhand.
}

\footnotetext{
ABSTRACT

Diabetes is one of the important public health problem. There are currently 415 million people affected worldwide and number is increasing day by day to an epidemic proportion. Diabetes is a lifestyle related metabolic disorder; besides genetic factor other risk factors are also involved in causation. Gravity of situation is compounded by the fact that fifty percent cases of diabetes remain undiagnosed until complication appear. A change in lifestyle, weight reduction, activity and improved awareness about diabetes can delay diabetic related complication.
}

\section{METHODS}

A cross-sectional questionnaire based interview of 450 patients was carried out in diabetic OPD of Dr. Susheela Tiwari Memorial Hospital associated with Government Medical College, Haldwani, Nainital, Uttarakhand. The question regarding patient's demographic characteristic and awareness of various aspect of diabetes including general knowledge, cause, complication and prevention were asked.

\section{RESULT}

In present study, $302(67.1 \%)$ knew what diabetes is. Most of the patients, i.e. $383(85.1 \%)$ patients in present study were not aware about symptoms of diabetes. Among studied patients, 249 (55.3\%) did not know that diabetes can cause ocular complication. Nearly half (48.8\%) patients were not aware about the cause of diabetes; 168 (37.3\%) patients were not aware about specific organ involvement in diabetes. The main source of awareness about diabetes was family members and friends, i.e. 201 (44.7\%). A large number of patients $(\mathrm{n}=215,47.7 \%)$ were not aware about preventive measure of diabetes.

\section{CONCLUSION}

This study clearly indicates that despite a good literacy rate, patient's knowledge about preventive measures is still low. There is a need to improve awareness regarding diabetes and its different aspect in the community.

\section{KEYWORDS}

Awareness, Diabetes Mellitus, Systemic and Ocular Complication, Questionnaire-Based Survey, Kumaon.

HOW TO CITE THIS ARTICLE: Satyawali V, Pandey S, Sharma V, et al. Assessment of level of awareness for diabetes mellitus, its systemic and ocular complications: a questionnaire-based survey at tertiary care centre of Kumaon region. J. Evolution Med. Dent. Sci. 2016;5(68):4856-4860, DOI: 10.14260/jemds/2016/1104

\section{INTRODUCTION}

Diabetes mellitus is now one of the prominent public health problems of twenty first century. It currently affects 415 million people worldwide, which is expected to increase to 642 million by the year 2040. At present, 67 billion dollars which is 12 percent of global health expenditure is spent on diabetes related treatment in a year. The greatest burden of the disease is felt by underdeveloped and developing countries, which account for 80 percent of all diabetes cases. ${ }^{1}$

In South-East Asia, 78.3 million people are living with diabetes which is expected to increase to 140.2 million by the

Financial or Other, Competing Interest: None.

Submission 02-08-2016, Peer Review 13-08-2016,

Acceptance 16-08-2016, Published 23-08-2016.

Corresponding Author:

Dr. Shanti Pandey,

Associate Professor,

Department of Ophthalmology,

Type 4, K2, Medical College Campus,

Haldwani, Nainital, Uttarakhand.

E-mail: drshantipandey@gmail.com

DOI: $10.14260 /$ jemds/2016/1104 year 2040. There are 69.1 million adult with diabetes (20-79 years) in India at present. The prevalence rate of diabetes in India is $8.7 \%$, which is expected to double by the year 2040.1

The gravity of situation is aggravated by the fact that 50 percent of the cases remain undiagnosed until complications appear. Among known cases of diabetes, the glycaemic control is not adequate due to lack of awareness. A constantly high blood glucose level can lead to serious disease, affecting heart, kidney, eyes, nerves and other systems. A good control of diabetes with improved awareness and knowledge can help delay or prevent diabetes related complications. People with diabetes are 25 times more likely to become blind in comparison to normal population. ${ }^{2}$

Diabetes besides retinal involvement may cause blindness due to cataract, glaucoma, optic nerve involvement and macular degeneration. ${ }^{3}$ Studies have shown that most diabetics do not follow the advised ocular examination at regular interval. ${ }^{4}$ Similarly a regular work-up for other macro and microvascular complications of diabetes is needed for early detection and prevention of complications related 
morbidity. It is obvious that diabetic patients should have sufficient knowledge and awareness regarding diabetes and its effect. This will help patients to practice positive behaviour for prevention, detection and management of diabetes related complication.

There is no study from our region in this regard. Although, there have been small regional studies on the subject of diabetes awareness in India, 4,5,6 there is no data at a national level or indeed even in a whole state of India on the awareness about diabetes.

Therefore, this study was undertaken to survey the level of awareness regarding general knowledge of diabetes and its complications.

\section{MATERIAL AND METHODS \\ Study Area}

The study was conducted out in Diabetic Clinic of Dr. Susheela Tiwari Memorial Hospital, a teaching hospital associated with Government Medical College, Haldwani, Nainital, Uttarakhand.

\section{Duration of Study}

December 2014-November 2015.

\section{Study Population}

All diabetic patients with age $>16$ years who were willing to participate in the study were selected. A sample size of 450 patients was calculated.

\section{Ethical Consideration}

A prior approval was taken from the Institutional Ethical Committee.

\section{Study Design}

Prospective, cross-sectional, questionnaire-based study was conducted in selected patients. Local spoken language was used in the questionnaire. Help was provided to the patient, who could not read the questionnaire.

A basic demographic detail of the patients (e.g. age, sex, location, occupation, duration of diabetes) was recorded. It also includes questions regarding general knowledge and awareness of diabetes, its causes, complication, ocular complication, management and prevention.

\section{RESULT}

A total of 450 patients were screened from Diabetic Clinic having diabetes.

\section{Age and Sex Distribution}

Out of 450 patients who participated in the study, 247 (54.8\%) were male and $203(45.1 \%)$ were female (M:F=1.2:1). Most of diabetic patients $(49.11 \%)$ were in $41-60$ years' age group. Most of the males (42.1\%) and females (57.6\%) were in age group of 41-60 years. In 16-40 years' age group numbers of male patients were higher in comparison to female (Table 1).

\section{Distribution According to Occupation}

Out of 247 male patients, largest number 117 (47.4\%) were clerk. While in female group, out of 203 patients 106 (52.2\%) were unemployed (housewife) (Table 2).

\section{Distribution According to Educational Status}

In present study, most patients were metric pass $(40 \%)$ or graduates (33.33\%), while only $48(10 \%)$ were uneducated in present study (Table 3).

\section{Duration of Diabetes}

Most of the patients, 198 (44\%) in present study were having diabetes since 1-5 years followed by 166 (36.9\%) patients were diabetic for duration of 6-10 years. Least number 27 $(6 \%)$ of patients were having diabetes for less than one year (Chart 1).

\section{Types of Diabetes among Study Population}

$70.2 \%$ of cases were of type 2 diabetes mellitus followed by type 1 and others (Chart 2).

\section{Knowledge about Diabetes}

In present study, 302 (67.1\%) patients knew what diabetes is. When asked about control of blood sugar in last one year, 263 (58.4\%) patients said that they have adequate control of blood sugar; 118 (26.3\%) patients were aware about use of insulin in diabetes. Most of the patients (85.1\%) in present study were not aware about symptoms of diabetes; 201 (44.6\%) knew that diabetic cause ocular complications (Table 5).

\section{Awareness of Cause of Diabetes}

When enquired about causes of diabetes, 220 (48.8\%) patients were not aware about cause of diabetes, while 118 (26.2\%) patients believe that it results due to high sugar intake and 72 (16\%) patients were aware of familial aspect of diabetic causation. Only $40(8.8 \%)$ patients were aware about true scientific cause of diabetes (Table 6).

\section{Awareness of Involvement of Different Body Parts in Diabetes}

In answer to question which body organ involved in diabetes, $201(44.6 \%)$ were aware about eye involvement, 176 (39.1\%) were about heart, 122 (27.1\%) were aware about kidney and $36(8 \%)$ were aware about nerve involvement. Only $24(5.3 \%)$ patients were aware about more than one organ involvement, while $168(37.3 \%)$ patients were not aware of any organ involvement in diabetes (Table 7).

\section{Awareness about Ocular Involvement in Diabetes}

Most of the participants, i.e. 249 (55.3\%) patients were not aware of eye involvement. Out of 201 patients who were aware about the eye involvement in diabetes, 161 (25.8\%) were aware of only retinal involvement in diabetes, while $30(6.6 \%)$ patients were aware of only lens involvement; 10 (2.2\%) patients were aware of both retinal and lens involvement in diabetes (Table 8).

\section{Source of Awareness about Diabetes}

In answer to question what is the source of knowledge of diabetes, 154 (34.2\%) said from doctor, 201 (44.7\%) got knowledge from family member and friends and 95 (21.1\%) gained information from newspaper, electronic media and internet (Table 9).

\section{Awareness about Preventive Measures}

$47.7 \%$ said that they did not know how to prevent it and $40 \%$ think that less consumption of sugars can prevent diabetes, but very few patients know that exercise (4.8\%) and weight reduction $(3.3 \%)$ can prevent it effectively (Table 10 ). 


\begin{tabular}{|c|c|c|c|}
\hline Age & No. of Male (\%) & No. of Female (\%) & Total (\%) \\
\hline $16-40$ & $45(18.2)$ & $20(9.8)$ & $65(14.4)$ \\
\hline $41-60$ & $104(42.1)$ & $117(57.6)$ & $221(49.11)$ \\
\hline $61-80$ & $80(32.3)$ & $60(29.5)$ & $140(31.1)$ \\
\hline$>80$ & $18(7.3)$ & $6(2.9)$ & $24(5.3)$ \\
\hline Total & $\mathbf{2 4 7}(54.8)$ & $\mathbf{2 0 3}(45.1)$ & $\mathbf{4 5 0}$ \\
\hline \multicolumn{4}{|c|}{ Table 1: Distribution According to Age and Sex } \\
\hline
\end{tabular}

\begin{tabular}{|c|c|c|c|}
\hline Occupation & $\begin{array}{c}\text { No. of } \\
\text { Male (\%) }\end{array}$ & $\begin{array}{c}\text { No. of } \\
\text { Female (\%) }\end{array}$ & $\begin{array}{l}\text { Total } \\
\text { (\%) }\end{array}$ \\
\hline Officer & $21(8.5)$ & $10(4.9)$ & $31(6.8)$ \\
\hline Clerk & $117(47.4)$ & $50(24.6)$ & $167(37.1)$ \\
\hline Trader & $19(7.7)$ & $2(0.98)$ & $21(4.6)$ \\
\hline Farmer & 70 (28.3) & 35 (17.24) & $105(23.3)$ \\
\hline Unemployed & $20(8.1)$ & $106(52.2)$ & $126(28)$ \\
\hline Total & 247 & 203 & 450 \\
\hline
\end{tabular}

\begin{tabular}{|c|c|c|c|}
\hline $\begin{array}{c}\text { Educational } \\
\text { Status }\end{array}$ & $\begin{array}{c}\text { No. of Male } \\
\text { (\%) }\end{array}$ & $\begin{array}{c}\text { No. of Female } \\
\text { (\%) }\end{array}$ & Total \\
\hline Graduate & $90(36.4 \%)$ & $60(29.6 \%)$ & $150(33.3 \%)$ \\
\hline Metric & $100(44.4 \%)$ & $80(39.4 \%)$ & $180(40 \%)$ \\
\hline $\begin{array}{c}\text { Primary } \\
\text { Education }\end{array}$ & 27 (10.9\%) & $45(22.2 \%)$ & $72(16 \%)$ \\
\hline Uneducated & $30(12.1 \%)$ & $18(8.9 \%)$ & $48(10.6 \%)$ \\
\hline Total & 247 & 203 & 450 \\
\hline
\end{tabular}

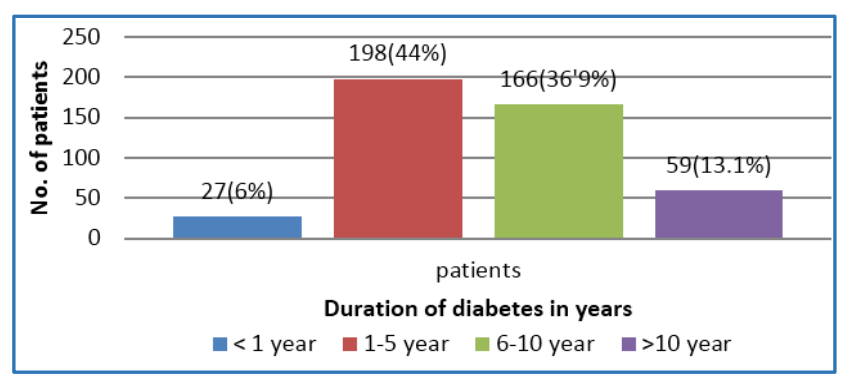

Chart 1: Showing Duration of Diabetes

\begin{tabular}{|c|c|c|c|}
\hline \multirow{2}{*}{$\begin{array}{c}\text { Type of } \\
\text { Diabetes }\end{array}$} & $\begin{array}{c}\text { Number of } \\
\text { Patient (\%) } \\
\text { (Total No. of } \\
\text { Patients-450) }\end{array}$ & \multicolumn{2}{|c|}{$\begin{array}{c}\text { Patient's Knowledge } \\
\text { about } \\
\text { Type of Diabetes }\end{array}$} \\
\cline { 3 - 4 } & Yes & No \\
\hline Type II DM & $325(70.2 \%)$ & $47(14.5 \%)$ & $278(85.5 \%)$ \\
\hline Type I DM & $76(16.8 \%)$ & $30(39.5 \%)$ & $46(60.5 \%)$ \\
\hline OTHER & $49(12.8 \%)$ & $7(14.3 \%)$ & $42(85.7 \%)$ \\
\hline \multicolumn{3}{|c|}{$\begin{array}{c}\text { Table 4: Distribution of Types of } \\
\text { Diabetes among Study Population }\end{array}$} \\
\hline
\end{tabular}

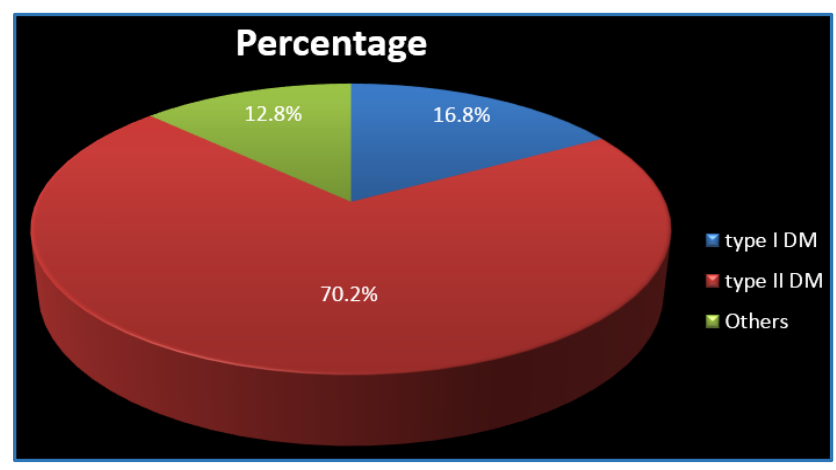

Chart 2: Distribution of Types of Diabetes among Study Population

\begin{tabular}{|c|c|c|}
\hline \multirow{2}{*}{$\begin{array}{l}\text { Knowledge about } \\
\text { what Diabetes is? }\end{array}$} & Yes & No \\
\hline & $302(67.1 \%)$ & $148(32.8 \%)$ \\
\hline \multirow{2}{*}{$\begin{array}{c}\text { Control of } \\
\text { Blood Sugar }\end{array}$} & Controlled & Uncontrolled \\
\hline & $263(58.4 \%)$ & $187(41.5 \%)$ \\
\hline \multirow{2}{*}{$\begin{array}{l}\text { Patients using } \\
\text { Insulin }\end{array}$} & Yes & No \\
\hline & $118(26.3 \%)$ & $332(73.7 \%)$ \\
\hline \multirow{2}{*}{$\begin{array}{c}\text { Awareness about } \\
\text { Symptoms of Diabetes }\end{array}$} & Yes & No \\
\hline & $67(14.8 \%)$ & $383(85.1 \%)$ \\
\hline \multirow{2}{*}{$\begin{array}{c}\text { Knowledge that Diabetes } \\
\text { can cause Ocular } \\
\text { Complications }\end{array}$} & Yes & No \\
\hline & $201(44.6 \%)$ & $249(55.3 \%)$ \\
\hline \multicolumn{3}{|c|}{ Table 5: Knowledge about Diabetes } \\
\hline \multicolumn{3}{|c|}{ Awareness about Cause of Diabetes } \\
\hline Not Aware & \multicolumn{2}{|c|}{\begin{tabular}{l|l} 
& $220(48.8 \%)$ \\
\end{tabular}} \\
\hline High Sugar Intake & \multicolumn{2}{|c|}{$118(26.2 \%)$} \\
\hline Familial Cause & \multicolumn{2}{|c|}{$72(16 \%)$} \\
\hline Scientific Reason & \multicolumn{2}{|c|}{$40(8.8 \%)$} \\
\hline \multicolumn{3}{|c|}{$\begin{array}{c}\text { Table 6: Showing Awareness } \\
\text { of Cause of Diabetes }\end{array}$} \\
\hline
\end{tabular}

\begin{tabular}{|c|c|}
\hline Part of Body & $\begin{array}{l}\text { Knowledge about } \\
\text { Organ Involved }\end{array}$ \\
\hline Eyes & $201(44.6 \%)$ \\
\hline Heart & $176(39.1)$ \\
\hline Kidney & $122(27.1 \%)$ \\
\hline Nerve & $36(8 \%)$ \\
\hline More than one organ & $24(5.3 \%)$ \\
\hline Not Aware & $168(37.3 \%)$ \\
\hline \multicolumn{2}{|c|}{$\begin{array}{c}\text { Table 7: Showing Awareness of Involvement } \\
\text { of Different Body Parts in Diabetes }\end{array}$} \\
\hline
\end{tabular}

\begin{tabular}{|c|c|c|c|c|}
\hline $\begin{array}{c}\text { Part of Eye } \\
\text { Involved }\end{array}$ & $\begin{array}{c}\text { Only } \\
\text { Retina }\end{array}$ & $\begin{array}{c}\text { Only } \\
\text { Lens }\end{array}$ & Both & None \\
\hline $\begin{array}{c}\text { No. of } \\
\text { Patients }\end{array}$ & $\begin{array}{c}161 \\
(35.8 \%)\end{array}$ & $\begin{array}{c}30 \\
(6.6 \%)\end{array}$ & $\begin{array}{c}10 \\
(2.2 \%)\end{array}$ & $\begin{array}{c}249 \\
(55.3 \%)\end{array}$ \\
\hline \multicolumn{4}{|c|}{ Table 8: Showing Awareness about } \\
Ocular Involvement in Diabetes \\
\hline
\end{tabular}

\begin{tabular}{|c|c|}
\hline $\begin{array}{c}\text { Source of Knowledge } \\
\text { about Diabetes }\end{array}$ & $\begin{array}{c}\text { Number of } \\
\text { Patients }\end{array}$ \\
\hline Doctor & $154(34.20 \%)$ \\
\hline Family and Friends & $201(44.7 \%)$ \\
\hline Media & $95(21.1 \%)$ \\
\hline Table 9: Showing Source of \\
Awareness about Diabetes
\end{tabular}

\begin{tabular}{|c|c|}
\hline Awareness about Prevention & Number (\%) \\
\hline Not known & $215(47.7 \%)$ \\
\hline Less Sweets & $180(40 \%)$ \\
\hline Exercise & $22(4.8 \%)$ \\
\hline Good Food Habit & $18(4 \%)$ \\
\hline Weight Reduction & $15(3.3 \%)$ \\
\hline $\begin{array}{c}\text { Table 10: Showing Awareness about Preventive } \\
\text { Measures among Different Study Participants }\end{array}$ \\
\hline
\end{tabular}

\section{DISCUSSION}

Diabetes mellitus is a significant cause of mortality and morbidity, uncontrolled diabetes may lead to macro and microvascular complications. Education and awareness is the integral part of diabetic management. 
This study was undertaken to evaluate the alertness of DM among patients attending the diabetic clinic at our hospital as well as to determine the predictors of awareness/knowledge of diabetes. The specific objectives were to assess how wellinformed our study participants were regarding diabetes, its causes, management, complications and its prevention.

Gender association was depicted in some studies; however, in some other studies there was no gender predilection. In our study, $58.4 \%$ were males showing that diabetes is slightly more in males. But this is a hospital-based study and does not represent actual prevalence in community.

The mean age of onset of diabetes among the patients was after the fourth decade of life.

Study participants were mostly having diabetes for 1-10 years duration. There were only $13.1 \%$ patients having diabetes for more than 10 years; decreased number of diabetic may be due to increased mortality resulting from diabetic associated complication.

Despite having good literacy rate in study population, (73.3\% of the patients have educational status, matriculate of more), $85.1 \%$ patients were not aware about symptoms of diabetes and $41.5 \%$ patients did not have adequate control of blood sugar. But more than half (67.1\%) patients were aware about what the diabetes is. These findings are contrary to the findings of Muninarayana et al, who reported that $50 \%$ of diabetic patients in Tamaka, Kolar (India) had no knowledge of diabetes. ${ }^{6}$ Similar findings have also been reported from Kenya. ${ }^{7}$ This discrepancy may be due to the good literacy rate and inclusion of urban population in our study. Also with time, awareness was increased in population. Our study shows that knowledge of symptoms of diabetes is less $(14.6 \%)$, which is comparable to study of Mohan D et al. ${ }^{5}$ The regional differences in level of awareness of diabetes could be attributed to differences in the education levels.8,9

Majority of diabetic patients in our study were employed as clerks having sedentary lifestyle as compared to farmers who are usually moderate of heavy workers. Similar results have been shown by Muninarayana et al. ${ }^{6}$ Similarly, Foma et al also shows that sedentary lifestyle is a risk factor for diabetes. ${ }^{10}$

Most of the patients were educated up to metric and a good number of patients were graduate as well. High number of educated class in present study may be reflection of high literacy rate of the state; many studies have shown relationship between literacy rate and awareness regarding diabetes.

Almost half of the participants (48.8\%) were not aware what causes diabetes. Common belief that high sugar/sweet intake cause diabetes was also reflected in this study and $26.2 \%$ patients reported it as a cause of diabetes. Few participants (8.8\%) knew the scientific reason, such as lack of insulin or failure of the body to use insulin. This finding is in agreement with that of Unadike et al, who reported that only few respondents in Uyo (Nigeria) knew that lack of insulin can cause diabetes. ${ }^{11}$ It is striking to discover that about $16 \%$ of our study participants knew that diabetes could be familial. This finding is consistent with that of Hashmi et al, who reported that most patients in Lahore (India) were unaware that diabetes runs in the family. ${ }^{12}$

Awareness for organ involvement was highest for eye (44.6\%) followed by heart (39.1\%) and kidney (27.1\%). But a good number of patients $(37.3 \%)$ were not aware that diabetes can involve any organ in the body. Therefore, there is a need to instruct patients on these complications as this may persuade them to adopt corrective measures that may be vital in managing the disease in order to prevent these complications. Deepa Mohan et al in Chennai observed that even among self-reported diabetic subjects, knowledge about diabetes including awareness of complications of diabetes was poor. 13

In our study large no. of patients (55.5\%) were not aware about ocular involvement of diabetes, which is in contrast to study by Goodwin et al, ${ }^{14}$ where only $18.2 \%$ patients were not aware about ocular complication.

In nearly half $(44.7 \%)$ the source of information about diabetes were their family members and friends and in only $34.2 \%$ patients source of information was treating doctor. There is need for doctors to counsel properly and need for media to propagate it by due attention.

Burden in the society can only be decreased by making people aware about preventive aspects of disease. Exercise and weight reduction are the proven ways to delay/prevent diabetes, especially type II which is much more common. Most complications of diabetes can be prevented with modification of food habits, exercise, lifestyle changes. The use of medications is advised for individuals in whom suitable glycaemic level cannot be reached with the above measures. 15 Most of the patients (47.7\%) were not aware about this preventive aspect of diabetes in present study. Only $4.8 \%$ and $3.3 \%$ patients were aware about beneficial effect of exercise and weight reduction respectively and are consistent with the findings of Baskin et al in rural Tanzania. ${ }^{16}$ Similar observations have been reported from India, ${ }^{11}$ Oman $^{17}$ and Tanzania. ${ }^{16}$ There is therefore a need for more educational campaigns to promote modification of lifestyles as well as adherence to exercise and dietary prescription. Such campaigns should be simplified to enable individuals with low educational status to understand the messages.

Education about risk factors, complications, diet control, physical activity, regular check-ups and screening will help in achieving better control of diabetes and thus reduce the burden due to diabetes complications. The National Program for Control of Diabetes, Cardiovascular Disease and Stroke is presently being implemented all over the country and this program can help improve diabetes awareness levels at a national level. 18

Although present study was conducted by making appropriate question banks regarding the disease. A bias related to interviewer and participants must be considered. Secondly, responses to most questions (e.g. duration of illness, co-morbidities, etc.) were self-reported and no references was made to medical reports/charts, as these credentials were barely available. This dependence on self-reporting may be prone to "recall bias."

\section{CONCLUSION}

Diabetes is an important health issue in India. For its management and prevention, patient's knowledge about its causes and prevention and associated misconceptions need to be tackled. This study clearly indicates that despite a good literacy, patient's knowledge about preventive measures is still low. There must be proper campaigns by government and media to enhance knowledge of population for diabetes 
prevention. Appropriate counselling by doctors about disease is important, which is not properly done.

\section{REFERENCES}

1. Cavan D, Fernandes JDR, Makaroff L, et al. IDF diabetes atlas. $7^{\text {th }}$ edn. International Diabetes Federation 2015.

2. Thomann KH, Marks ES, Adamczyk DT. Primary eye care in systemic disease. New York, McGraw-Hill 2001:189204.

3. Jeganathan VS, Wang JJ, Wong TY. Ocular associations of diabetes other than diabetic retinopathy. Diabetes Care 2008;31(9):1905-12.

4. Mumba M, Hall A, Lewallen S. Compliance with eye screening examinations among diabetic patients at a Tanzanian referral hospital. Ophthalmic Epidemiol 2007;14(5):306-10.

5. Murugesan N, Snehalatha C, Shobhana R, et al. Awareness about diabetes and its complications in the general and diabetic population in a city in Southern India. Diabetes Res Clin Pract 2007;77(3):433-7.

6. Muninarayana C, Balachandra G, Hiremath SG, et al. Prevalence and awareness regarding diabetes mellitus in rural Tamaka, Kolar. Int J Diabetes Dev Ctries 2010 ;30(1):18-21.

7. Kiberenge MW, Ndegwa ZM, Njenga EW. Knowledge, attitude and practices related to diabetes among community members in four provinces in Kenya: a crosssectional study. Pan Afr Med J 2010;7(2):15-8.

8. Caliskan D, Ozdemir 0, Ocaktan E, et al. Evaluation of awareness of diabetes mellitus and associated factors in four health center areas. Patient Educ Couns 2006; 62(1):142-7.

9. Viswanathan $V$, Shobhana R, Snehalatha C, et al. Need for education on footcare in diabetic patients in India. J Assoc Physicians India 1999;47(11):1083-5.
10. Foma MA, Saidu Y, Omoleke SA, et al. Awareness of diabetes mellitus among diabetic patients in the Gambia: a strong case for health education and promotion. BMC Public Health 2013;13:1124. http://www.biomedcentral.com/1471-2458/13/1124.

11. Unadike BC, Chineye S. Knowledge, awareness and impact of diabetes among adolescents in Uyo, Nigeria. African Diabetes Int 2009;17:12-4.

12. Hashmi NR, Daud S, Manzoor I. Awareness among individuals attending outpatient department of Ghurki trust teaching hospital. Professional Med J 2008;5(1): 96-100.

13. Mohan D, Raj D, Shanthirani CS, et al. Awareness and knowledge of diabetes in Chennai - the Chennai Urban Rural Epidemiology Study (CURES-9). J Assoc Physicians India 2005;53:283-7.

14. Ovenseri-Ogbomo GO, Abokyi S, Koffuor GA, et al. Knowledge of diabetes and its associated ocular manifestations by diabetic patients: a study at Korle-Bu Teaching Hospital, Ghana. Niger Med J 2013;54(4): 217-23.

15. Alberti KGMM, Zimmet PZ. Definition, diagnosis and classification of diabetes mellitus and its complications. Part 1: Diagnosis and classification of diabetes mellitus. Provisional report of a WHO consultation. Diabet Med 1998;15(7):539-53.

16. Avi B, Colford J. Prevalence and treatment of diabetes in rural Tanzania. Berkeley: University of California at Berkeley Press 2012.

17. Al-Shafaee MA, Al-Shukaili S, Rizvi SGA, et al. Knowledge and perceptions of diabetes in a semi-urban Omani population. BMC Public Health 2008;8(1):249.

18. Ministry of Health and Family Welfare. National programme for prevention and control of diabetes, cardiovascular disease and stroke. A manual for medical officers 2016. 